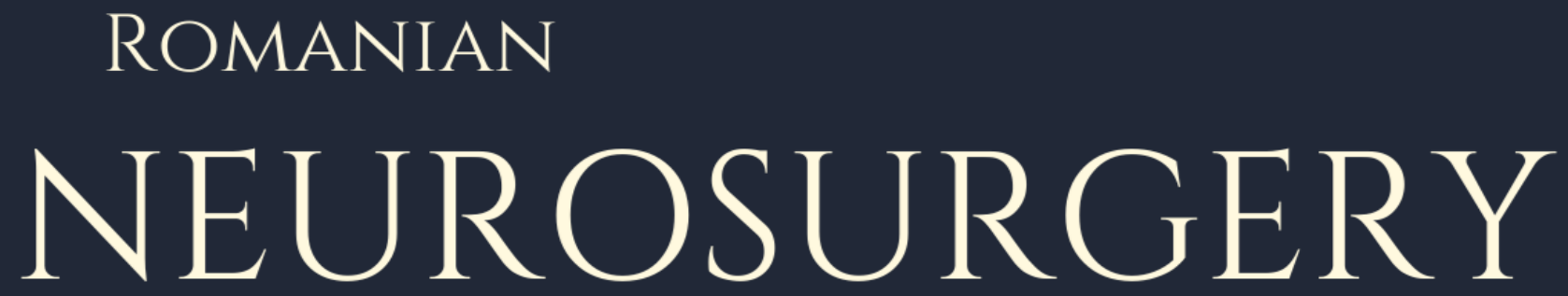

$$
\text { Vol. XXXIV | No. } 1 \quad \text { March } 2020
$$

Glioblastoma of septum pellucidum

Rajneesh Misra,

Sushil Kumar,

Kundan Kumar 


\title{
Glioblastoma of septum pellucidum
}

\author{
Rajneesh Misra, Sushil Kumar, Kundan Kumar
}

Dept. of Neurosurgery, St. Stephens Hospital, Tis Hazari, Delhi, INDIA

\begin{abstract}
A rare case of glioblastoma multiforme (GBM) of septum pellucidum is being reported. There were symptoms of altered behaviour, memory and changes in sensorium. The MRI was suggestive of a tumour arising from the septum pellucidum. Glioblastomas arising from septum pellucidum are rare. While even a partial endoscopic excision of the more common pathology viz. colloid cyst is acceptable, only, a safe maximal excision of a highly malignant pathology like glioblastoma is an acceptable goal in order to give any benefit of surgical exploration to the patient.
\end{abstract}

\section{INTRODUCTION}

Glioblastoma multiforme (GBM) is a common primary brain tumor accounting for nearly $15-20 \%$ of all intracranial tumors. (1) Lee and Manzano enumerated the most common tumors in the intraventricular tumors and the GBM doesn't find a mention in the first fourteen. (2) The table 1 below summarizes all such tumors in the intraventricular location.

Usually it involves frontal or temporal lobe and involvement of septum pellucidum is very rare. Hence the present case is being reported.

\section{CASE REPORT}

A 70-year-old male was admitted with inappropriate behavior and talking of 20 days duration and impaired memory with progressive drowsiness of 4 days duration. On higher mental function testing, he talked irrelevantly, and did not recognize relatives. On physical examination, the tone was increased in all the four limbs and the GCS was E2V3M5. The deep tendon reflexes were brisk.

MRI revealed a mass lesion in relation to septum pellucidum and bulging into right lateral ventricle (Fig 1). A right frontal craniotomy and a trans-cortical entry into the ventricle revealed tumor arising from septum pellucidum postero-superior to the foramen of Monroe. The tumor was soft, suckable and moderately vascular. It was infiltrative in nature. He did not improve neurologically after surgery. Post-operative radiotherapy was suggested but the family members were not willing for the same. Histo-pathology was suggestive of diagnosis of grade IV glioma (glioblastoma multiforme).

\section{Keywords}

glioblastoma multiforme, septum pellucidum. transcortical approach

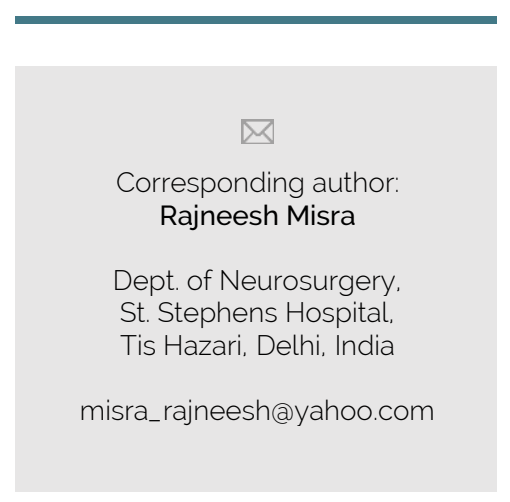

Copyright and usage. This is an Open Access article. distributed under the terms of the Creative Commons Attribution Non-Commercial No Derivatives License (https://creativecommons org/licenses/by-nc-nd/4.0/) which permits noncommercial re-use, distribution, and reproduction in any medium, provided the original work is unaltered and is properly cited

The written permission of the Romanian Society of Neurosurgery must be obtained for commercial re-use or in order to create a derivative work.

ISSN online 2344-4959

(C) Romanian Society of Neurosurgery

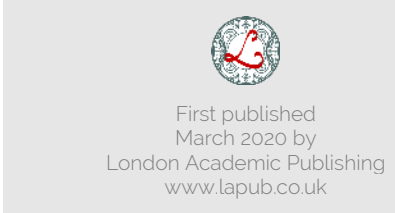



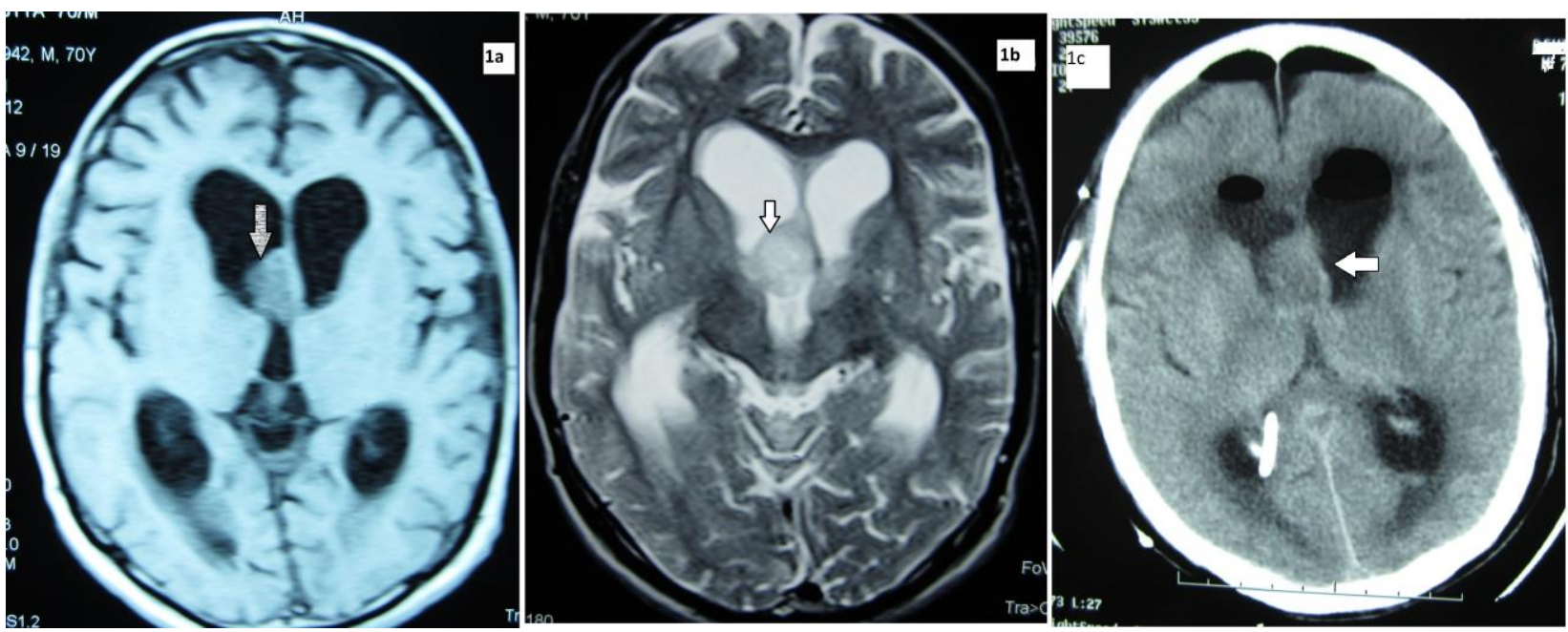

Figure 1. (1a) Axial T1 plain MRI showing iso- to hypo-intense lesion occupying the lower margin of septum pellucidum; (1b) The same lesion on T2 shows hyper-intensity; (1c) Post-operative CT brain showing pneumocephalus and residual lesion.

\section{DISCUSSION}

GBM is one of the most common tumors encountered in neurosurgical practice. It usually involves the region of centrum semiovale with preference for frontal and temporal lobes. Involvement of the septum pellucidum by a tumor is a rare occurrence as it usually gets involved by a spread from the surrounding structures in the lateral ventricles, thalamus or fornices. Septum pellucidum is a part of limbic system and forms a relay between corpus callosum and fornix. This is classically known to have functions involving emotions, consciousness and memory. Structurally, it contains glial cells, neurons and veins connecting to choroid plexus. (4) Multiple theories have been proposed regarding the origin of GBM in this region. The most often quoted origin is that from ependyma which separated early during differentiation and later migrated towards ventricular cavity. A less commonly mentioned hypothesis states that the tumor originates elsewhere in the CNS and spreads to septum pellucidum and third ventricle through the CSF. (5) However, in our case, there was no evidence of tumor elsewhere. Galli et al. in their paper in 2004 proposed another interesting mechanism invoking the progenitor neural stem cells from the subventricular zone. (6) They observed that the subventricular progenitor stem cells are known to migrate to fimbrial fornix in injury. (7) A similar mechanism could work for spread of the tumour.

Only two of the nine cases of GBM reported in the lateral ventricles were seen to be arising from the septum pellucidum (8).Majority of the cases of GBM of septum reported have been from autopsy series. $(9,10,11)$ Choi et al reported GBM of pellucidum on autopsy in a 41 year old woman. (11)

GBM of septum pellucidum arises from the neuroglial cells of the septum and lateral ventricles. (2) There is no pathognomonic feature of the GBM of septum pellucidum GBM. Headache, visual deficits, signs of raised intracranial pressure, memory disturbances and personality changes are the features that can occur with any lesion causing slowly progressive rise in ICP. Patient's impaired memory could be explained by involvement of the limbic system pathways. (12) Therefore, diagnosing a high grade lesion of septum pellucidum on clinical grounds is extremely unlikely.

On imaging, GBM is known exhibit aggressive features including evidence of vasogenic edema, necrosis and mass effect. None of these features were present in our case. It is possible that, due to strategic location of the lesion, it became symptomatic due to obstructive hydrocephalus before it could attain enough size to show evidence of its own mass effect or have undergo necrosis. Computed tomography of such septal lesions shows irregular hypo-density with widening of the septum. MRI usually shows enhancing ring with central hypointense area, although we did not find such appearance in our case. (8) Epstein and Epstein reported a widened septum pellucidum on pneumoventriculogram and GBM of septum pellucidum and corpus pellucidum on necropsy. (10) MRI can 
diagnose the cases with indentation of septum and unilateral or bilateral mass arising from septum as demonstrated in our case. Reasonable differentials to be considered due to location of the lesion include central neurocytoma, subependymal giant cell astrocytoma and intraventricular meningioma.

Surgical de-bulking followed by radiotherapy is the standard treatment. However, attendants of the patient were not keen on radiotherapy when educated about the prognosis of the GBM.

\section{CONCLUSIONS}

The standard treatment for glioblastoma is safe maximal decompression followed by chemoradiotherapy. However, glioblastoma arising from septum pellucidum is distinctly rare occurrence. It offers an opportunity for a more thorough decompression. However, this is possible if the clinician holds reasonable suspicion about the nature of the lesion and opts for intraoperative frozen section to guide the surgical decision making.

The authors declare no conflict of interests.

No funding was obtained for producing this work.

\section{REFERENCES}

1. Lopes MBS, VandenBerg SR, Scheithauer BW: Histopathology, immunochemistry and ultrastructure of brain tumors. In Kaye AH, Laws ER Jr, editirs. Brain tumors. 1st ed. NewYork: Churchill Livingstone; 1995.pp $125-162$.
2. Lee TT, Manzano GR: Third ventricular glioblastoma multiforme; case report. Neurosurg Rev 1997; 20: 291294.

3. Wen PY, Kesari S. Malignant gliomas in adults. N Engl J Med 2008; 359(5):492-507.

4. Sarnat HB, NetskyMG. Evolution of the Nervous System. New York,NY: Oxford University Press; 1974.

5. Prieto R, Pascual JM, Roda JM. Third ventricle glioblastoma. Case report and review of literature. Clin Neurol Neurosurg 2006;108(2):199-204.

6. Galli $R$, Binda $E$, Orfanelli $U$, et al. Isolation and characterization oftumorigenic, stem-like neural precursors from human glioblastoma.Cancer Res 2004;64(19):7011-7021.

7. Steffenhagen C, Dechant FX, Oberbauer E, et al. Mesenchymal stem cells prime proliferating adult neural progenitors toward an oligodendrocyte fate. Stem Cells Dev 2012;21(11):1838-1851.

8. Secer HI, Dinc C, Anik I, Duz B, GonulE :Glioblastoma of multiforme of lateral ventricle: report of nine cases. $\mathrm{Br}$ J Neurosurg 2008;22(3):398-401.

9. Chusid JG, and Gutierrez-Mahoney C: Glioblastomamultiforme of of septum pellucidum. J Neurosurg 1954;11(3):251-257.

10. Epstein JA and Epstein BS: Glioblastomamultiforme of bith the septum pellucidum and the corpus callosum. J Neurosurg1957;14(6):688-692.

11. ChoiSK,Byun BJ, Lee IS and Chi JG: Glioblastomamultiforme of the septum pellucidum: An autopsy case report. J Korean Neurosurg Soc. 1980;9(2):497-504.

12. McKean-Cowdin R, Razavi P, Barrington-Trimis J, et al. Trends in childhood brain tumor incidence: 1973-2009. J Neurooncol 2013;115(2):153-160. 